\title{
Global carbon dioxide removal potential of waste materials from metal and diamond mining
}

\author{
LIAM BULLOCK ${ }^{1}$, RACHAEL H JAMES ${ }^{2}$, JUERG \\ MATTER $^{1}$, PHIL RENFORTH ${ }^{3}$, AIDONG YANG ${ }^{4}$, RICHARD \\ DARTON $^{4}$ AND DAMON TEAGLE ${ }^{1}$ \\ ${ }^{1}$ University of Southampton \\ ${ }^{2}$ School of Ocean and Earth Science \\ ${ }^{3}$ Heriot-Watt University \\ ${ }^{4}$ University of Oxford \\ Presenting Author: liam.bullock@eng.ox.ac.uk
}

There is growing urgency for $\mathrm{CO}_{2}$ removal strategies that can slow the increase of, and potentially lower, atmospheric $\mathrm{CO}_{2}$ concentrations. Enhanced weathering, whereby the natural reactions between $\mathrm{CO}_{2}$ and silicate minerals that produce dissolved bicarbonate ions (alkalinity) are accelerated, has the potential to capture and sequester atmospheric $\mathrm{CO}_{2}$ in substantial quantities on decadal to centennial timescales.

Here we investigate the $\mathrm{CO}_{2}$ removal potential of the enhanced weathering of waste materials generated by global mining activities. Demand for metal and diamond resources continues to grow, and it is imperative for the mining industry to reduce its net carbon footprint. The global mining industry produces huge volumes of finely ground tailings that have a large potential as feedstock for enhanced weathering. The fine grainsizes (10-1000 $\mu \mathrm{m})$ of tailings provides large amounts of freshly exposed reactive surface area that can increase mineral dissolution rates. Critically, the global mining industry is the only sector with the knowledge and equipment to repurpose the huge quantities of materials required for $\mathrm{CO}_{2}$ removal through enhanced weathering. If effective $\mathrm{CO}_{2}$ removal schemes could be provided at mine sites, it would greatly improve the carbon footprint of the mining industry.

We have compiled a global database of the enhanced weathering potential of mined metal and diamond wastes from silicate-hosted deposit types worldwide. Our aim is to identify tailings-types with the highest enhanced weathering potential to help target engineering efforts for $\mathrm{CO}_{2}$ removal schemes via alkalinity generation. Our data indicate that mafic and ultramafic rock-hosted mining operations and high tonnage $\mathrm{Cu}$-hosting deposits have the potential to capture the equivalent of the mining industry's direct annual $\mathrm{CO}_{2}$ emissions. Overall, $\mathrm{CO}_{2}$ removal via alkalinity generation at mine sites could be a major contributor of negative carbon emissions and potentially accommodate a significant portion of the reductions required to meet 2050 Paris Agreement climate targets. However, as dissolution rates of many minerals are relatively slow, we estimate that only a fraction of this potential may be realised by mid-century. New approaches to accelerate mineral dissolution, such as improved tailings management practices and enhancing the $\mathrm{CO}_{2}$ content of the reacting fluid, are urgently required. 